\title{
The dopamine antagonist domperidone increases prolactin concentration and enhances milk production in dairy cows
}

\author{
P. Lacasse ${ }^{1}$ and S. Ollier \\ Dairy and Swine Research and Development Centre, Agriculture and Agri-Food Canada, Sherbrooke, Quebec, Canada J1M 0C8
}

\begin{abstract}
In previous studies, our team showed that the inhibition of prolactin (PRL) secretion by the dopamine agonist quinagolide reduces milk production in dairy cows. The objective of this study was to determine the effects of administration of a dopamine antagonist on basal and milking-induced PRL concentrations in blood and on milk production during positive energy balance and feed restriction in dairy cows. Eighteen mid-lactation Holstein cows received daily s.c. injections of either domperidone (300 mg, DOMP, $\mathrm{n}=9$ ) or the vehicle, canola oil (CTL, $\mathrm{n}=9$ ), for 5 wk. During wk 5 , all cows were fed at $65 \%$ of their dry matter intake in the previous week. Blood and milk samples were collected before (for blood) and during (for milk) the a.m. milking thrice weekly from $\mathrm{d}-9$ to 41 ( $8 \mathrm{~d}$ after the last injection). In addition, blood samples were collected during the a.m. milking on $\mathrm{d}-1$ (before the first injection), and on d 1, 28, and 34. Basal PRL concentration was similar in both groups before the start of the treatments. Domperidone injections caused a gradual increase in basal PRL concentration. Feed restriction reduced basal PRL concentration in both the CTL and DOMP cows, but PRL concentration remained higher in the DOMP cows. Prolactin concentration remained elevated in the DOMP cows $7 \mathrm{~d}$ after the last injection. The milk concentration of PRL increased during the DOMP treatment, but the increase was smaller than that observed in serum. In the CTL cows, the milking-induced PRL release above the premilking concentration was similar on $\mathrm{d}-1,1$, and 28 but was reduced during feed restriction. In the DOMP cows, the milking-induced PRL release was similar on $\mathrm{d}-1$ and 1 but was reduced on d 28 and 34. Milk production was similar for both groups before the treatments started but was greater in the DOMP cows during the treatment period, at $2.9 \pm 0.6$ and $2.4 \pm 0.6 \mathrm{~kg} / \mathrm{d}$ greater
\end{abstract}

Received May 26, 2015.

Accepted July 6, 2015.

${ }^{1}$ Corresponding author: pierre.lacasse@agr.gc.ca during wk 3 and 4 of treatment, respectively. Milk production declined in both groups during feed restriction but remained higher in the DOMP cows. Milk production became similar again for both groups after the last injection. In addition, dry matter intake was increased by DOMP. These results support the hypothesis that PRL is galactopoietic in dairy cattle.

Key words: prolactin, feed restriction, lactation persistency, galactopoiesis

\section{INTRODUCTION}

Prolactin (PRL), as its name implies, is the most important hormone for the control of lactation. In most mammals, the suppression of PRL with bromocriptine strongly inhibits lactation (Taylor and Peaker, 1975; Flint and Gardner, 1994). Although the involvement of PRL in the control of ruminant lactation has been controversial, our team recently demonstrated that the administration of quinagolide, a more specific and more potent PRL-release inhibitor than bromocriptine, decreased milk production in dairy cows (Lacasse et al., 2011; Ollier et al., 2013, 2014, 2015) and that PRL injection attenuated the inhibitor effect (Lacasse et al., 2012). In those studies, even though the basal level of PRL was not clearly associated with the level of milk production, the milking-induced PRL release was correlated with the level of milk production in both PRLinhibited and control cows. Interestingly, our team observed that feed restriction depresses blood PRL concentration (Ollier et al., 2014, 2015), which suggests that feed restriction may affect the mammary gland by modifying PRL concentration. Further evidence of the galactopoietic action of PRL is provided by the finding that a long-day photoperiod increased PRL concentration and milk production (Bilodeau et al., 1989). Nevertheless, a complete demonstration of the galactopoietic function of PRL requires showing that pharmacologically enhanced PRL concentration has a positive effect on lactation.

The main physiological control of PRL secretion is exerted by the inhibitory action of dopamine on the lactotrophs of the anterior pituitary via dopamine 
D2 receptors (Torre and Falorni, 2007). Dopamine is secreted in the hypothalamus through the tuberoinfundibular dopamine pathway and reaches the pituitary through a portal vascular system. It has been proposed that suckling reduces the activity of the neurons in the tuberoinfundibular dopamine pathway, enabling the release of PRL into the bloodstream (Li et al., 1999). Domperidone (DOMP) is a dopamine antagonist that has been shown to induce PRL secretion in several species, including rat (Kato et al., 1980), human (Fujino et al., 1980), and sheep (Deaver et al., 1987). The oral administration of DOMP has been shown to enhance milk production in women (da Silva et al., 2001) and mares (Cross et al., 2012). Therefore, the objective of this study was to determine the effect of DOMP injections on PRL secretion and milk production during positive energy balance and feed restriction in dairy cows.

\section{MATERIALS AND METHODS}

\section{Animals and Experimental Design}

The experiment was conducted in accordance with the guidelines of the Canadian Council on Animal Care (1993). Eighteen Holstein cows (187 \pm 13 DIM) were housed in a tiestall barn at Agriculture and Agri-Food Canada's Dairy and Swine Research and Development Centre (Sherbrooke, QC, Canada). The cows received daily (at 1030 h) s.c. injections of either domperidone (DOMP, $\mathrm{n}=9$ ) or the vehicle, canola oil (control, CTL, $\mathrm{n}=9$ ), for 5 wk. Domperidone (300 mg, Equi-Tox Inc., Central, SC) was injected as an oil suspension in 10 $\mathrm{mL}$ of canola oil. During wk 5, all cows were fed at $65 \%$ of their DMI in the previous week. The cows were milked twice daily, at 0800 and $2000 \mathrm{~h}$, and milk yield was recorded at each milking. The animals were fed a TMR containing (on a DM basis) $34 \%$ corn silage, $21 \%$ grass silage, $17.2 \%$ corn grain, $15.6 \%$ soybean meal, $4.5 \%$ chopped dry hay, $3.6 \%$ beet pulp, $1.8 \%$ nonmineral supplement, $1.7 \%$ mineral supplement, and $0.5 \%$ calcium carbonate. Feed intake was recorded daily. The BW of each animal was determined at the start and at the end of the experiment.

Caudal blood samples were collected before the a.m. milking $3 \mathrm{~d} /$ wk from $\mathrm{d}-9$ to 41 ( $8 \mathrm{~d}$ after the last injection) using uncoated Vacutainer tubes (Becton, Dickinson and Co., Rutherford, NJ). On d -1 (before the start of the treatments), and d 1, 28, and 34, samples were collected from 6 cows per treatment in tubes without additives before, during, and after the a.m. milking $(-20,-10,0,3,5,7,10,15,20,25,30$, 40 , and $60 \mathrm{~min}$ relative to the start of milking) from a Silastic catheter (i.d. $1.02 \mathrm{~mm}$, o.d. $2.16 \mathrm{~mm}$; Dow Corning Corp., Midland, MI) inserted into the jugular vein. The blood tubes were left for approximately $2 \mathrm{~h}$ at room temperature for clotting before centrifugation $\left(1,900 \times g, 4^{\circ} \mathrm{C}, 15 \mathrm{~min}\right)$. Serum samples were then kept at $-20^{\circ} \mathrm{C}$ until determination of PRL and NEFA concentrations.

Milk samples were collected at the a.m. milking $3 \mathrm{~d} /$ wk from d -9 to 41 . Milk lactose, protein, and fat concentrations and SCC were determined in a commercial laboratory (Valacta Inc., Ste-Anne-de-Bellevue, QC, Canada). In addition, aliquots of the milk samples were skimmed by centrifugation $\left(1,900 \times g, 4^{\circ} \mathrm{C}, 15 \mathrm{~min}\right)$ and stored at $-20^{\circ} \mathrm{C}$ until determination of PRL concentration.

\section{PRL and Metabolite Concentrations}

Serum and milk PRL concentrations were measured by RIA as described by Bernier-Dodier et al. (2011). Bovine PRL, rabbit antiserum specific for bovine PRL, and goat anti-rabbit gamma globulin were purchased from the National Hormone and Peptide Program (Harbor-UCLA Medical Center, Torrance, CA). Serum concentration of NEFA was determined using NEFAHR(2) reagents (Wako Diagnostics, Richmond, VA) as described by Ollier et al. (2014).

\section{Statistical Analysis}

Data were analyzed by ANOVA using the MIXED procedure of the SAS software package (SAS Institute Inc., Cary, NC). Time was used as a repeated effect, and animal was used as the subject. Data were analyzed separately for the pretreatment period $(\mathrm{d}<1)$, each week of the treatment period ( 1 to 28 ), the feedrestriction period (d 29 to 35), and the posttreatment period $(\mathrm{d}>35)$. Means of the data from the pretreatment period were used as covariates. The amount of PRL released into the blood during milking was calculated by determining the area under the curve between 0 and 40 min relative to the start of milking, and basal PRL concentration was calculated by averaging the concentrations obtained between -20 and 0 min. The proportion of steady-state PRL secreted via milk, which equals the amount of PRL secreted via milk in $24 \mathrm{~h}$ multiplied by 100 and divided by the amount of PRL present in the circulation, was calculated according to Singh et al. (2014). Differences were considered statistically significant when $P<0.05$ and considered a trend when $P<0.15$.

\section{RESULTS}

Serum PRL concentration was not different for both groups of cows before the treatments began $(P>0.8$; 
Figure 1A). The concentration of PRL gradually increased (treatment $\times$ day, $P=0.02$ ) in the DOMPtreated cows and was greater $(P<0.01)$ in those cows than in the CTL cows from d 6 to the end of the treatment period (d 28). Feed restriction caused a reduction in PRL concentration in both DOMP and control cows $(P<0.01)$. Nevertheless, PRL concentration remained greater $(P<0.001)$ in DOMP cows than in CTL cows during feed restriction. Although DOMP injections ended on d 33, PRL concentration remained greater in the DOMP cows a week later $(P=0.02)$.

Milk PRL concentration did not differ for both groups of cows before the treatments began $(P=0.22$; Figure 1B). The concentration of PRL was greater $(P$ $<0.001)$ in the DOMP-treated cows than in the CTL cows during the treatment period (until d 28). Feed restriction did not affect milk PRL concentration, which remained greater $(P<0.001)$ in the DOMP cows than in the CTL cows during this period. As was the case for serum, milk PRL concentration remained greater in the DOMP cows than in the CTL cows a week after the last injection $(P<0.01)$. The proportion of steady-state PRL secreted via milk was not different in both groups before the treatments began $(P>0.8$; Figure 1C) but was greater in the CTL cows than in the DOMP cows during the treatment $(P<0.001)$, feed-restriction $(P=$ $0.04)$, and posttreatment $(P=0.05)$ periods.

Milking-induced PRL release in the blood was measured on $\mathrm{d}-1$ (before treatments), $\mathrm{d} 1,28$, and 34 (after $6 \mathrm{~d}$ of feed restriction; Figure 2). During the $\mathrm{d}-1$ and 1 milkings, the total amount of PRL released was not different in both groups of animals (Table 1). In the CTL cows, the amount of PRL released (area under the curve above the baseline value) at milking was maintained on d 28. Conversely, in the DOMP cows, milking-induced PRL release was blunted by the increase in the basal concentration. During feed restriction, the basal concentration of PRL was lower than at d 28 in both groups of cows $(P<0.01)$ but remained greater in the DOMP cows than in the CTL cows. In both treatments, the amount of PRL released at milking was not significant on d $34(P>0.7)$.

Milk production was not different in both groups of cows before the treatments began (Figure 3). During the treatment period, milk production was greater $(P$ $<0.01)$ in the cows injected with DOMP, being 2.9 \pm 0.6 and $2.4 \pm 0.6 \mathrm{~kg} / \mathrm{d}$ greater during wk 3 and 4 of treatment, respectively. Feed restriction caused a reduction in milk production $(P<0.001)$ in both treatments. We detected a treatment $\times$ day interaction $(P$ $=0.05)$, with milk production being not different in both groups during the first $2 \mathrm{~d}$ and greater $(P<0.05)$ in the DOMP cows for the remainder of the restriction period. Milk production increased after the feed restriction and treatments ended $(P<0.001)$ in both the DOMP and CTL cows and tended to be greater in the DOMP cows $(P=0.10)$.

Milk fat, protein, and lactose contents were not different before the treatments began $(P>0.1$; Table 2). Milk fat and lactose contents were not affected by the treatments or feed restriction $(P>0.15)$. Milk protein content was lower $(P<0.05)$ in the milk of the DOMP cows during the treatment, feed-restriction, and posttreatment periods.

Dry matter intake was not different in both groups before the treatments began $(P=0.7$; Figure 4$)$. During the treatment period, DMI was greater $(P<0.02)$ in the DOMP cows. After feed restriction, DMI was similar in both groups. Body weight change during the experiment tended $(P=0.12)$ to differ for the 2 groups, averaging 0.5 and $-11.2 \mathrm{~kg}$ for the CTL and DOMP cows, respectively.

Serum concentration of NEFA was not different for both treatments before feed restriction (data not shown). During feed restriction, NEFA increased $(P<$ $0.001)$ in both groups, and there was a trend $(P=$ $0.09)$ toward a greater concentration in the blood of the DOMP cows, averaging 351.8 and $436.5 \pm 38 \mathrm{~m} M$ for the CTL and DOMP cows, respectively.

\section{DISCUSSION}

As shown in other species, the injection of DOMP caused a sustained increase in PRL concentration in serum of dairy cows. This increase was gradual, and PRL concentration remained elevated several days after the last injection. Because of its low solubility in water, DOMP was administered s.c. as an oil suspension, which probably resulted in slow release of the compound. Indeed, i.v. infusion of DOMP in a solution of water and dimethyl sulfoxide induces a sharp increase in PRL concentration (B. Ponchon, McGill University, Montreal, Canada; X. Zhao, McGill University; and P. Lacasse; unpublished results).

Milking-induced PRL release was greatly reduced by DOMP. In previous studies, the short-term (2.5-h) infusion of PRL did not affect milking-induced PRL release (Tucker et al., 1973), but the release was reduced after $13 \mathrm{~d}$ of PRL injections (Plaut et al., 1987). Prolactin secretion is normally regulated by a short-loop negative feedback mechanism, whereby PRL increases dopamine secretion into the pituitary portal blood by tuberoinfundibular neurons (Grattan et al., 2008). However, PRL-induced secretion of dopamine by these neurons is strongly blunted during lactation, allowing a state of hyperprolactinemia to occur (Romanò et al., 2013). 

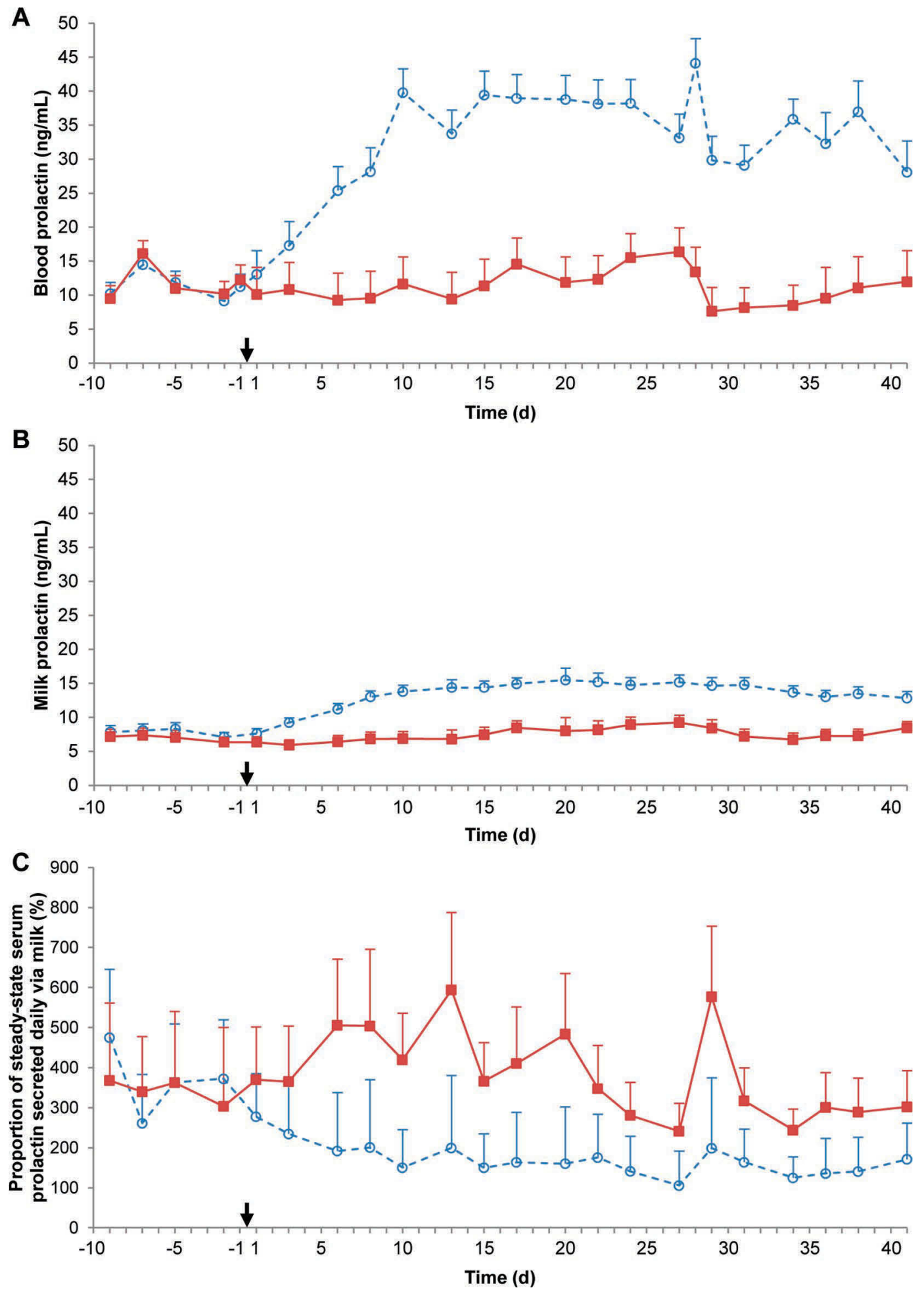

Figure 1. Basal concentration of prolactin in the blood (A) and milk (B) and proportion of steady-state serum prolactin secreted daily via milk (C) of dairy cows injected daily s.c. with $300 \mathrm{mg}$ of domperidone $(\mathrm{O}$, short-dashed line; $\mathrm{n}=9)$ or canola oil $($ control, $\mathbf{\square}$, solid line; $\mathrm{n}=9)$ for $34 \mathrm{~d}$. Cows were feed-restricted (65\% of the previous week's DMI) from d 29 to 35 . The start of injections is indicated by an arrow. Data are presented as LSM \pm SEM. Color version available online. 

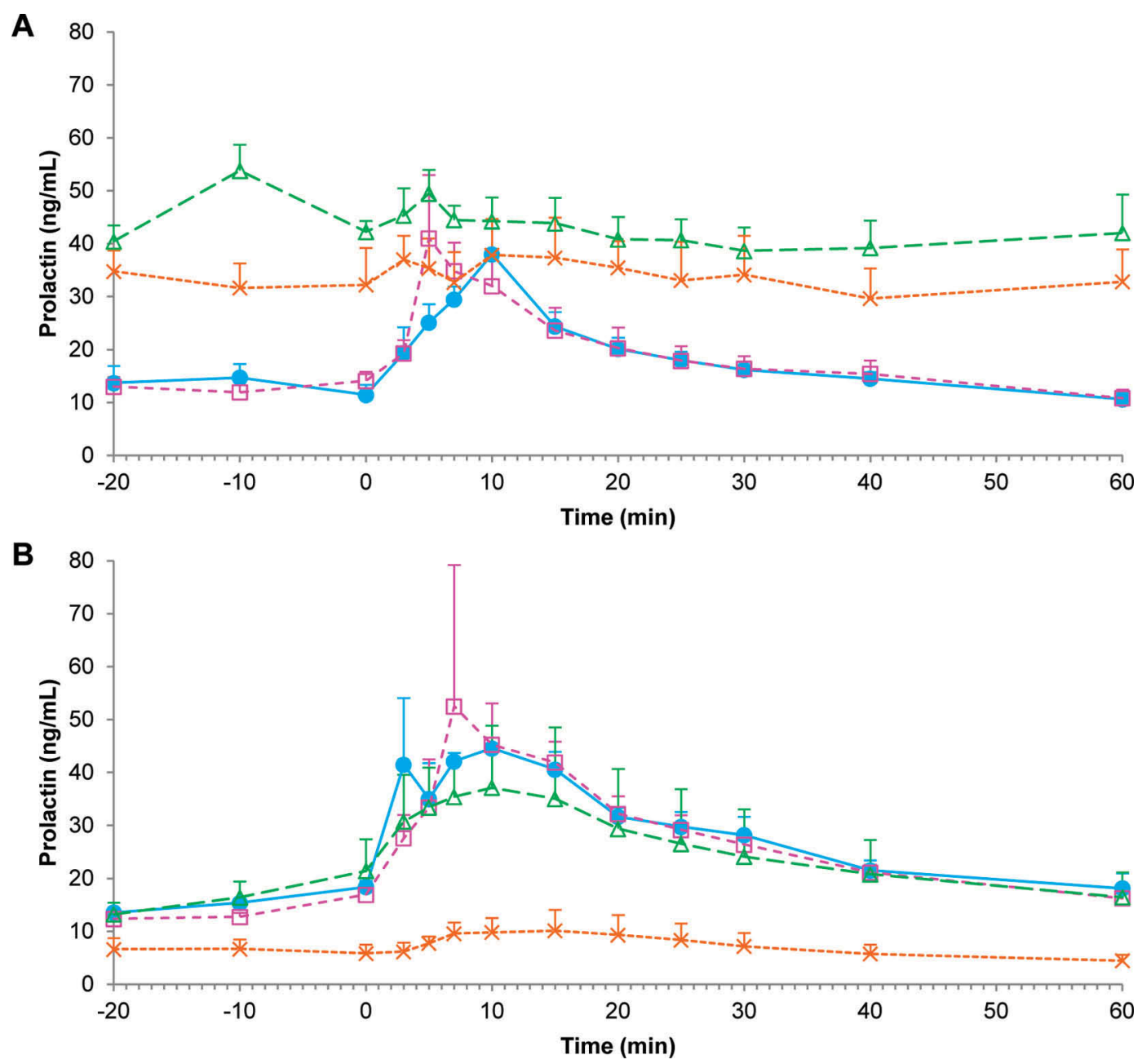

Figure 2. Milking-induced release of prolactin on $\mathrm{d}-1(\bullet$, solid line), 1 ( $\square$, short-dashed line), $28(\Delta$, long-dashed line), and $34(\times$, dotted line) in the blood of dairy cows injected daily s.c. with $300 \mathrm{mg}$ of domperidone $(\mathrm{A} ; \mathrm{n}=6)$ or canola oil (control, B; $\mathrm{n}=6)$ for $34 \mathrm{~d}$. Cows were feed-restricted (65\% of the previous week's DMI) from d 29 to 35. Data are presented as means \pm SEM. Color version available online.

Nevertheless, dopamine secretion is not abolished, given that DOMP, which is a dopamine antagonist, effectively enhances PRL secretion. Therefore, chronic exposure to high PRL concentrations may prevent a decrease in dopamine in portal circulation during milking. Another possibility is that PRL secretion is already high and the reduction in dopamine concentration in portal blood has little effect on PRL secretion by the pituitary.

Domperidone injections moderately enhanced milk production. In previous experiments, our team observed that quinagolide, a dopamine agonist, inhibited PRL secretion and milk production in dairy cows in early and late lactation (Lacasse et al., 2011; Ollier et al., 2013, 2014, 2015). Nevertheless, injecting cows in early-peak lactation with PRL for $14 \mathrm{~d}$ did not affect milk production in a previous study (Plaut et al.,
1987). In the present experiment, the effect on milk production was gradual and more apparent after $14 \mathrm{~d}$ of treatments, which suggests that the effects of providing PRL to normal cows may take longer than $14 \mathrm{~d}$ to become apparent. Accordingly, Wall et al. (2006) reported greater milk production in early-lactation cows injected with PRL twice daily for $3 \mathrm{wk}$. In addition, cows in early lactation show greater release of PRL at milking (Koprowski and Tucker, 1973) and may, therefore, be less responsive to exogenous PRL than cows in a later stage of lactation would be. Even in a species where PRL is clearly galactopoietic, such as swine (Farmer et al., 1998), the exogenous injection of PRL failed to increase milk production (Farmer et al., 1999), a result that illustrates the difficulty of demonstrating the galactopoietic effect of PRL by administering exogenous PRL to intact females. 
Milk concentration of PRL increased in the DOMP cows, but the efficiency of transfer of PRL from blood into milk was lower in these cows. Akers and Kaplan (1989) reported that the transfer of PRL from blood into milk was reduced by the intramammary infusion of colchicine, a result that suggests that PRL is transferred across the alveolar epithelium rather than between secretory cells. In goats, the transfer of ${ }^{125}$ I-labeled PRL into milk was found to be reduced when the level of endogenous PRL was high or when unlabeled PRL was infused and was enhanced by bromocriptine-induced hypoprolactinemia (Forsyth et al., 1995), a finding that indicates the presence of a competitive and saturable mechanism of transfer. Malven (1983) presented evidence that milk transfer of PRL plays a role in lactogenesis and postulated that it could also be involved in galactopoiesis. If that is the case, this transfer may contribute to the resistance of ruminant lactation to PRL manipulation.

Feed restriction reduced basal PRL concentration and milking-induced release of PRL in the blood. The reduction in basal concentration of PRL in feedrestricted dairy cows was reported previously (Vicini et al., 1988; Kuhla et al., 2010; Ollier et al., 2014, 2015). The fact that milk yield was also decreased in those studies raises the question of whether the reduction in PRL secretion plays a role in the inhibition of milk production. Serum PRL concentration in the DOMP cows decreased during feed restriction but remained greater than in the CTL cows before restriction. Milk production in the DOMP cows declined during feed restriction, although they still produced more milk than the CTL cows did. Nevertheless, NEFA concentration and $\mathrm{BW}$ loss tended to be greater in the DOMP cows, suggesting that those cows mobilized body reserves to a greater extent than the CTL cows did.

Domperidone increased DMI slightly. Although that increase could have occurred in response to the greater milk production, the injection of nonlactating female rats with PRL was also found to increase feed intake (Byatt et al., 1993; Sauvé and Woodside, 1996). Inhibiting PRL secretion by injecting quinagolide reduced the feed intake of dairy cows in previous studies (Lacasse et al., 2011; Ollier et al., 2014, 2015). The suckling stimulus activates neuropeptide $\mathrm{Y}$ neurons in the dorsomedial nucleus of the hypothalamus, an effect that was found to be reduced by bromocriptine and restored by ovine PRL (Li et al., 1999; Chen and Smith, 2004). Although they studied other species, Ingvartsen and Andersen (2000) proposed that neuropeptide Y plays an important role in the increase in feed intake in early lactation. Taken together, these results support the idea that PRL increases feed intake to provide the nutrients necessary to support lactation. 


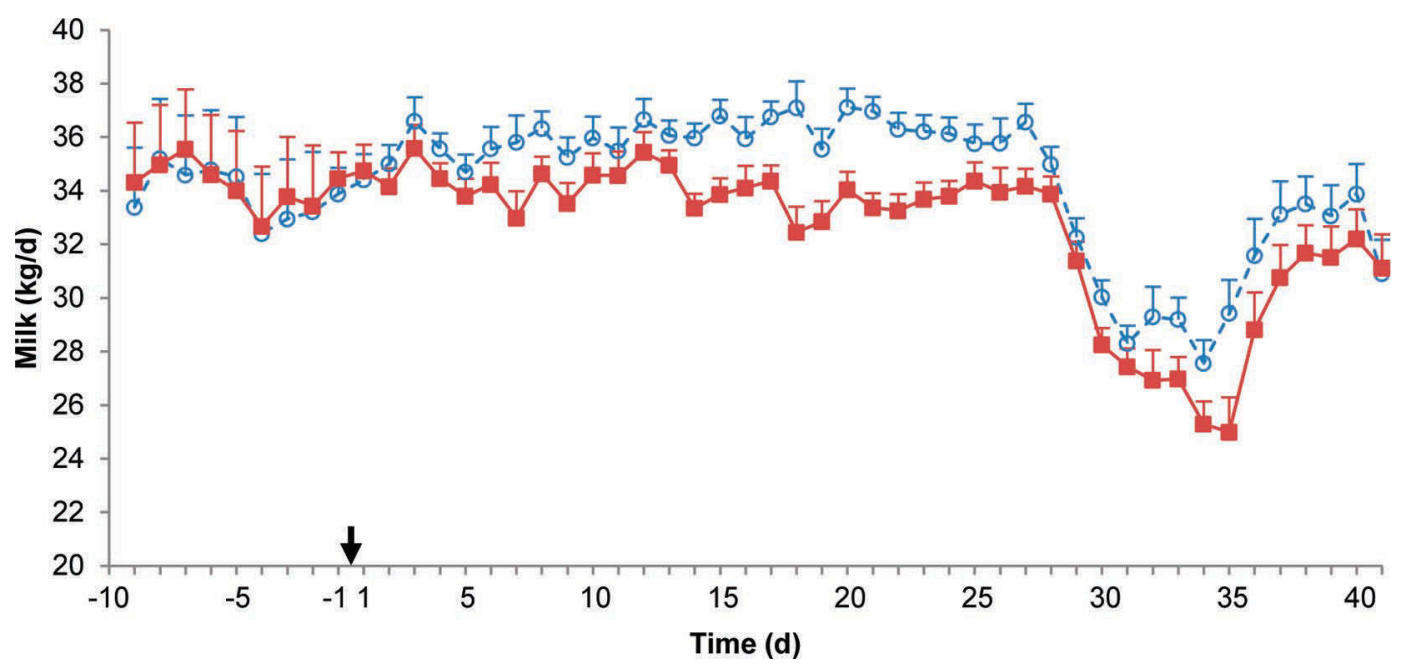

Figure 3. Milk production of dairy cows injected daily s.c. with $300 \mathrm{mg}$ of domperidone $(\bigcirc$, short-dashed line; $\mathrm{n}=9)$ or canola oil $($ control, , solid line; $\mathrm{n}=9$ ) for $34 \mathrm{~d}$. Cows were feed-restricted ( $65 \%$ of the previous week's DMI) from d 29 to 35 . The start of injections is indicated by an arrow. Data are presented as LSM \pm SEM. Color version available online.

In conclusion, the administration of DOMP increased PRL concentration and milk production, findings that support the hypothesis that PRL is galactopoietic in dairy cows. Feed restriction reduced basal and milkinginduced PRL release, but DOMP was not able to prevent milk production decline.

\section{ACKNOWLEDGMENTS}

The authors thank the following people from Agriculture and Agri-Food Canada (Sherbrooke, QC, Canada): Véronique Roy, Myriam Calvet, and Lucie Delgove for providing technical assistance; Steve Méthot for helping with statistical analyses; and the dairy barn staff for taking care of the animals. The authors are grateful to Mary Varcoe, from the Translation Bureau, Public Works and Government Services Canada, for her careful editing of this manuscript. The authors also thank A. F. Parlow and the National Hormone and Peptide Program (Torrance, CA) for providing the bovine prolactin and antibodies. This research was financially supported by Agriculture and Agri-Food Canada, the Dairy Farmers of Canada and the National Sciences and Engineering Research Council of Canada (Ottawa, ON, Canada).

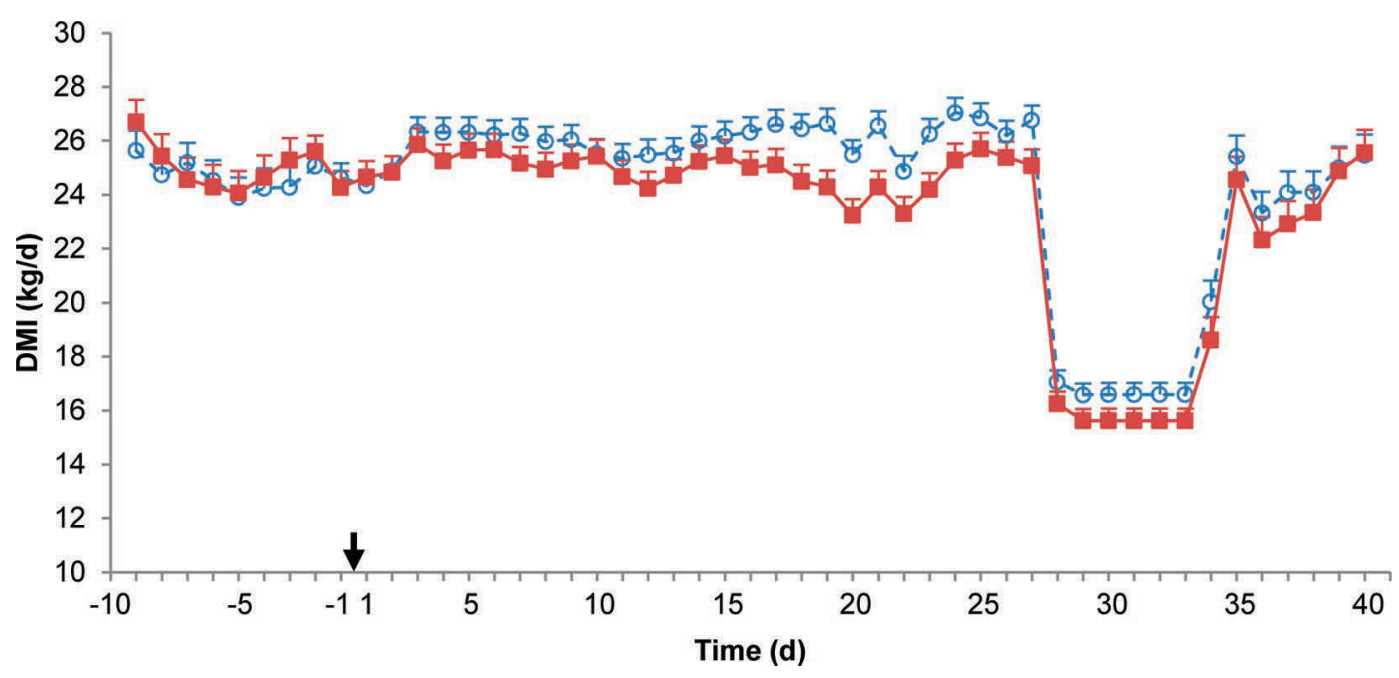

Figure 4. Dry matter intake of dairy cows injected daily s.c. with $300 \mathrm{mg}$ of domperidone $(\bigcirc$, short-dashed line; $\mathrm{n}=9)$ or canola oil $($ control, a, solid line; $\mathrm{n}=9$ ) for $34 \mathrm{~d}$. Cows were feed-restricted ( $65 \%$ of the previous week's DMI) from d 29 to 35 . The start of injections is indicated by an arrow. Data are presented as LSM \pm SEM. Color version available online. 


\section{REFERENCES}

Akers, R. M., and R. M. Kaplan. 1989. Role of milk secretion in transport of prolactin from blood into milk. Horm. Metab. Res. 21:362-365.

Bernier-Dodier, P., C. L. Girard, B. G. Talbot, and P. Lacasse. 2011. Effect of dry period management on mammary gland function and its endocrine regulation in dairy cows. J. Dairy Sci. 94:4922-4936.

Bilodeau, P. P., D. Petitclerc, N. St. Pierre, G. Pelletier, and G. J. St. Laurent. 1989. Effects of photoperiod and pair-feeding on lactation of cows fed corn or barley grain in total mixed rations. J. Dairy Sci. 72:2999-3005.

Byatt, J. C., N. R. Staten, W. J. Salsgiver, J. G. Kostelc, and R. J. Collier. 1993. Stimulation of food intake and weight gain in mature female rats by bovine prolactin and bovine growth hormone. Am. J. Physiol. 264:E986-E992.

Canadian Council on Animal Care. 1993. Guide to the Care and Use of Experimental Animals. Vol. 1. 2nd ed. E. D. Olfert, B. M. Cross, and A. A. McWilliam, ed. CCAC, Ottawa, ON, Canada.

Chen, P., and M. S. Smith. 2004. Regulation of hypothalamic neuropeptide Y messenger ribonucleic acid expression during lactation: Role of prolactin. Endocrinology 145:823-829.

Cross, D. L., C. R. Reinemeyer, J. C. Prado, R. L. Donnell, K. G. Bond, H. Farr, and S. L. Longhofer. 2012. Efficacy of domperidone gel in an induced model of fescue toxicosis in periparturient mares. Theriogenology 78:1361-1370.

da Silva, O. P., D. C. Knoppert, M. M. Angelini, and P. A. Forret. 2001. Effect of domperidone on milk production in mothers of premature newborns: A randomized, double-blind, placebo-controlled trial. CMAJ 164:17-21.

Deaver, D. R., D. H. Keisler, and R. A. Dailey. 1987. Effects of domperidone and thyrotropin-releasing hormone on secretion of luteinizing hormone and prolactin during the luteal phase and following induction of luteal regression in sheep. Domest. Anim. Endocrinol. 4:95-102.

Farmer, C., S. Robert, and J. Rushen. 1998. Bromocriptine given orally to periparturient or lactating sows inhibits milk production. J. Anim. Sci. 76:750-757.

Farmer, C., M. T. Sorensen, S. Robert, and D. Petitclerc. 1999. Administering exogenous porcine prolactin to lactating sows: Milk yield, mammary gland composition, and endocrine and behavioral responses. J. Anim. Sci. 77:1851-1859.

Flint, D. J., and M. Gardner. 1994. Evidence that growth hormone stimulates milk synthesis by direct action on the mammary gland and that prolactin exerts effects on milk secretion by maintenance of mammary deoxyribonucleic acid content and tight junction status. Endocrinology 135:1119-1124.

Forsyth, I. A., J. A. Taylor, G. Gabai, and I. R. Fleet. 1995. Blood prolactin concentrations affect prolactin transfer into goat milk: Implications for maintenance of lactation. J. Endocrinol. 146:411420 .

Fujino, T., H. Kato, S. Yamashita, S. Aramaki, H. Morioka, M. Koresawa, F. Miyauchi, H. Toyoshima, and T. Torigoe. 1980. Effects of domperidone on serum prolactin levels in human beings. Endocrinol. Jpn. 27:521-525.

Grattan, D. R., F. J. Steyn, I. C. Kokay, G. M. Anderson, and S. J. Bunn. 2008. Pregnancy-induced adaptation in the neuroendocrine control of prolactin secretion. J. Neuroendocrinol. 20:497-507.

Ingvartsen, K. L., and J. B. Andersen. 2000. Integration of metabolism and intake regulation: A review focusing on periparturient animals. J. Dairy Sci. 83:1573-1597.

Kato, H., T. Fujino, S. Aramaki, M. Koresawa, S. Yamashita, and T. Torigoe. 1980. The role of domperidone in the regulation of prolactin release in rats. Life Sci. 26:1343-1347.

Koprowski, J. A., and H. A. Tucker. 1973. Serum prolactin during various physiological states and its relationship to milk production in the bovine. Endocrinology 92:1480-1487.

Kuhla, B., D. Albrecht, R. Bruckmaier, T. Viergutz, G. Nürnberg, and C. C. Metges. 2010. Proteome and radioimmunoassay analyses of pituitary hormones and proteins in response to feed restriction of dairy cows. Proteomics 10:4491-4500. 
Lacasse, P., V. Lollivier, R. M. Bruckmaier, Y. R. Boisclair, G. F. Wagner, and M. Boutinaud. 2011. Effect of the prolactin-release inhibitor quinagolide on lactating dairy cows. J. Dairy Sci. 94:1302-1309.

Lacasse, P., V. Lollivier, F. Dessauge, R. M. Bruckmaier, S. Ollier, and M. Boutinaud. 2012. New developments on the galactopoietic role of prolactin in dairy ruminants. Domest. Anim. Endocrinol. 43:154-160.

Li, C., P. Chen, and M. S. Smith. 1999. Neuropeptide Y and tuberoinfundibular dopamine activities are altered during lactation: Role of prolactin. Endocrinology 140:118-123.

Malven, P. V. 1983. Transfer of prolactin from plasma into milk and associated physiological benefits to mammary cells. Endocrinol. Exp. 17:283-299.

Ollier, S., X. Zhao, and P. Lacasse. 2013. Effect of prolactin-release inhibition on milk production and mammary gland involution at drying-off in cows. J. Dairy Sci. 96:335-343.

Ollier, S., X. Zhao, and P. Lacasse. 2014. Effects of feed restriction and prolactin-release inhibition at drying off on metabolism and mammary gland involution in cows. J. Dairy Sci. 97:4942-4954.

Ollier, S., X. Zhao, and P. Lacasse. 2015. Effects of feed restriction and prolactin-release inhibition at drying-off on susceptibility to new intramammary infection in cows. J. Dairy Sci. 98:221-228.

Plaut, K., D. E. Bauman, N. Agergaard, and R. M. Akers. 1987. Effect of exogenous prolactin administration on lactational performance of dairy cows. Domest. Anim. Endocrinol. 4:279-290.

Romanò, N., S. H. Yip, D. J. Hodson, A. Guillou, S. Parnaudeau, S. Kirk, F. Tronche, X. Bonnefont, P. Le Tissier, S. J. Bunn, D. R.
Grattan, P. Mollard, and A. O. Martin. 2013. Plasticity of hypothalamic dopamine neurons during lactation results in dissociation of electrical activity and release. J. Neurosci. 33:4424-4433.

Sauvé, D., and B. Woodside. 1996. The effect of central administration of prolactin on food intake in virgin female rats is dose-dependent, occurs in the absence of ovarian hormones and the latency to onset varies with feeding regimen. Brain Res. 729:75-81.

Singh, S. P., S. Häussler, J. J. Gross, F. J. Schwarz, R. M. Bruckmaier, and H. Sauerwein. 2014. Short communication: Circulating and milk adiponectin change differently during energy deficiency at different stages of lactation in dairy cows. J. Dairy Sci. 97:1535-1542.

Taylor, J. C., and M. Peaker. 1975. Effects of bromocriptine on milk secretion in the rabbit. J. Endocrinol. 67:313-314.

Torre, D. L., and A. Falorni. 2007. Pharmacological causes of hyperprolactinemia. Ther. Clin. Risk Manag. 3:929-951.

Tucker, H. A., E. M. Convey, and J. A. Koprowski. 1973. Milkinginduced release of endogenous prolactin in cows infused with exogenous prolactin. Proc. Soc. Exp. Biol. Med. 142:72-75.

Vicini, J. L., W. S. Cohick, J. H. Clark, S. N. McCutcheon, and D. E. Bauman. 1988. Effects of feed intake and sodium bicarbonate on milk production and concentrations of hormones and metabolites in plasma of cows. J. Dairy Sci. 71:1232-1238.

Wall, E. H., H. M. Crawford, S. E. Ellis, G. E. Dahl, and T. B. McFadden. 2006. Mammary response to exogenous prolactin or frequent milking during early lactation in dairy cows. J. Dairy Sci. 89:4640-4648. 